\title{
Effect of Nanocrystalline Diamond Films Deflection on Wear Observed in Reciprocating Sliding Tests
}

\author{
V. Podgursky ${ }^{1, *}$, A. Bogatov ${ }^{1}$, S. Sobolev ${ }^{2}$, M. Viljus ${ }^{3}$, V. Sedov ${ }^{4,5}$, E. Ashkinazi ${ }^{4,5}$ and \\ V. Ralchenko ${ }^{4,5}$ \\ ${ }^{1}$ Department of Materials Engineering, Tallinn University of Technology, Ehitajate tee 5, 19086 Tallinn, Estonia \\ ${ }^{2}$ Gubkin Russian State University of Oil and Gas, Leninsky Prospect 65, 119991, Moscow, Russia \\ ${ }^{3}$ Centre for Materials Research, Tallinn University of Technology, Ehitajate tee 5, 19086 Tallinn, Estonia \\ ${ }^{4}$ Prokhorov General Physics Institute, Russian Academy of Sciences, Vavilova 38, 119991, Moscow, Russia \\ ${ }^{5}$ National Research Nuclear University MEPhl, Kashirskoe shosse 31, Moscow, 115409, Russia
}

\begin{abstract}
The present study deals with the tribological behavior of nanocrystalline diamond (NCD) films. The diamond films were deposited by microwave plasma enhanced chemical vapor deposition (MPCVD) in methane/hydrogen/air plasma on the $\mathrm{Si}(100)$ substrates. The tribological properties were studied by reciprocal sliding tests against $\mathrm{Si}_{3} \mathrm{~N}_{4}$ balls. The depth profiles and surface morphology of the wear scars were investigated by means of mechanical profilometry and scanning electron microscopy (SEM). Various adaptation processes occur between contacting surfaces including asperity polishing, formation of carbonaceous tribolayer and ripple patterns on the wear scar surfaces. The film deflection is the specific form of adaptation decreasing contact pressure and, therefore, the damage (including wear) of both counter bodies. The deflection of NCD films in sliding tests can be related with the effect of fatigue.
\end{abstract}

Received on 22-09-2016 Accepted on 03-11-2016 Published on 21-12-2016

Keywords: Diamond films, tribology, deflection, adaptation, self-organization.

DOI: http://dx.doi.org/10.6000/2369-3355.2016.03.03.2

\section{INTRODUCTION}

Diamond films are important engineering materials for tribological applications due to their outstanding properties including high hardness and Young's modulus, chemical inertness and wear resistance. Diamond films are used for tools protection [1], in manufacturing of microelectromechanical systems (MEMS) [2], surgical instruments [3], etc. Investigation of tribological properties of diamond films has attracted much attention in the past. The mostly influential factors affecting tribological performance of diamond films are as follows: anisotropy of mechanical and tribological properties [4, 5], formation of amorphous carbonaceous lubricating tribolayer [6, 7], ambient atmosphere [8, 9], surface morphology [10, 11], etc. Our previous studies [12-15] have reported the formation of morphological patterns on the wear scar surfaces including ripples and grooves after reciprocating sliding tests on

"Department of Materials Engineering, Tallinn University of Technology, Ehitajate tee 5, 19086 Tallinn, Estonia; Tel: +372 620 3358;

E-mail: vitali.podgurski@ttu.ee nanocrystalline diamond (NCD) and microcrystalline diamond (MCD) films deposited on Si (100) substrates. In the context of the present study, it is worth mentioning that the ripples were already found during run-in period [12, 14, 15]. Among other effects, the morphological adaptation of the contacting surfaces of the tribosystem occurs at this friction stage [16]. Wear on diamond is a load dependent process [6], therefore an increase in the area of the contacting surfaces of the counterbodies reduces the wear. To summarize, material fracture, micro-ploughing and asperities polishing wear mechanisms $[7,10,14,15,17]$, influence of ambient atmosphere $[8,9]$ on friction behavior and formation of carbonaceous tribolayer [7, 12] and morphological patterns [12-15] on the wear scar surfaces were observed during runin period on the diamond films.

The tribological system under investigation can be viewed as a thin hard film on a soft substrate. The load-carrying capacity of the film/substrate system is an ability to withstand pressure in the system without loss of the system functionality. This parameter strongly influences tribological 
behavior of the film/substrate system [18-20], however there is a lack of investigations of diamond films subjected to tribological contact $[14,15,17]$. The load-carrying capacity of the diamond like carbon (DLC)/substrate system depends on adhesion, internal stress, thickness and roughness of the film, hardness and Young's modulus of the film and substrate [20]. The load-carrying capacity of the film/substrate system is also a crucial aspect in understanding of the mechanics of plastic-elastic contact in nanoindentation measurements [21, 22].

The deflection of the NCD [14] and MCD [15, 17] films grown on the $\mathrm{Si}(100)$ substrates was observed after reciprocating sliding tests. The mechanisms underlying this phenomenon remain unclear. The properties of the substrate, diamond film and interface between them must be taken into account to realize the mechanisms contributing to the film deflection. It was suggested that following three factors could facilitate the $\mathrm{Si}(100)$ substrate deformation [14]. First, the dislocations network on the $\mathrm{Si}(100) /$ diamond film interface, which is formed during diamond film growth [23]. Second, the $\mathrm{Si}_{3} \mathrm{~N}_{4}$ ball is placed in contact with the edges of sharp diamond grains at the beginning of the test, thus the local contact pressure between the grains and ball can be underestimated in calculations assuming the ball in contact with the plain surface. Third, these contact spots act also as so-called frictional hot-spots [24] and high local temperature at these spots can account for the Si substrate mechanical properties variation. It is also instructive to consider wear related phenomena on the different size scales [18]. The Hertz contact pressure is calculated on the macro level (i.e. $\mathrm{mm}$ ), corresponding to the contact tribology [18], however different processes occurring on contact spots (hot-spots) between the ball and surface asperities are aspects of the asperity tribology (micro level, i.e. $\mu \mathrm{m}$ ) [18]. The deflection of diamond films occurs on the macro levels, as a part of the film located within the wear scar becomes deformed $[14,15,17]$.

The aim of this systematic study is to investigate the influence of the load, test duration and film thickness on the deflection of NCD films in sliding tests. The study focuses also on the understanding of the correlation between the wear and film deflection.

The growth mechanisms and surface morphology of the NCD films used in the current study were investigated in our recent work [25]. It was found that the surface morphology changes from the cusp-like to mountain-like and the surface roughness increases with increasing film thickness.

\section{EXPERIMENTAL}

The diamond films were deposited on $\mathrm{Si}(100)$ substrates in a microwave plasma CVD system ARDIS-100 $(2.45 \mathrm{GHz}, 5$ $\mathrm{kW}$ ) using a $\mathrm{CH}_{4} / \mathrm{H}_{2} /$ air mixture as the process gas, for the details of deposition see our publication [25]. The film thicknesses were 2.7, 4.8, 9 and $22 \mu \mathrm{m}$ and the surface roughness $S_{q}$ (root-mean-square) of the films was $55,62,63$ and $99 \mathrm{~nm}$, respectively.

Reciprocating sliding tests (normal load 0.5-3 N, displacement amplitude $1 \mathrm{~mm}$, frequency $5 \mathrm{~Hz}$, relative humidity about $50 \%$, ball diameter $\varnothing 3 \mathrm{~mm}$ ) were carried out by means of a CETR ${ }^{\circledR}$ UMT-2 tribometer. The test durations were 9000,36000 and 72000 cycles. $\mathrm{Si}_{3} \mathrm{~N}_{4}$ balls (surface roughness $\left.R_{a}=0.012 \mu \mathrm{m}\right)\left(\operatorname{REDHILL}^{\circledR}\right)$ were used as counter bodies. According to the producer provided data, the hardness, Young's modulus and Poisson ratio of the $\mathrm{Si}_{3} \mathrm{~N}_{4}$ counter bodies were 1400-1700 HV, $310 \mathrm{GPa}$ and 0.27, respectively. Monocrystalline $\mathrm{Si}(100)$ possesses a hardness of about $12 \mathrm{GPa}$ [26]; due to crystal anisotropy its Young's modulus varies along the (100) plane from about 130 [27] to 170-180 GPa [26, 27], the Poisson ratio is 0.278 [28], the fracture strength measured on $\mathrm{Si}(100)$ wafers is about 6.1 $\mathrm{GPa}[29]$.

Wear scars depth profiles were taken by stylus profilometry (Mahr Perthometer measuring system). Scanning electron microscopy (SEM) images were taken by a Zeiss $E V O^{\circledR}$ MA 15 system with LaB6 cathode in secondary electron mode, applying an accelerating voltage of $10-15 \mathrm{kV}$ and $6.5-8.5$ $\mathrm{mm}$ working distance.

The micro-Raman measurements were carried out on a Renishaw inVia micro-Raman setup equipped with an $\mathrm{Ar}+$ ion laser (514 $\mathrm{nm}$ wavelength).

\section{RESULTS AND DISCUSSION}

Figure 1 shows the coefficient of friction (COF) versus number of cycles curves. In the case of the tests with $0.5 \mathrm{~N}$, there are no considerable differences in friction behavior between 2.7, 4.8 and $9 \mu \mathrm{m}$ thick films, i.e. a steady state regime with the COF value about $0.13-0.16$ was observed after a transient period. Due to the relatively high roughness of the $22 \mu \mathrm{m}$ thick film, the run-in period is substantially longer for the test with $0.5 \mathrm{~N}$ in contrast to one with $2 \mathrm{~N}$. For the tests performed at higher loads ( 2 and $3 \mathrm{~N}$ ), a wider variability of COF values was found in the steady-state wear regime depending on the film thickness, see Figure $1 \mathbf{b}$. The highest COF value in the steady-state regime was observed for the smoothest and thinnest $2.7 \mu \mathrm{m}$ thick film, i.e. about 0.2 for the test with $2 \mathrm{~N}$. An exfoliation (catastrophic wear) of this film was observed in the tests with the load of $3 \mathrm{~N}$ and the duration longer than 3000 cycles.

Figure 2 shows SEM images taken on the surface of asdeposited $22 \mu \mathrm{m}$ thick NCD film (Figure 2a) and wear scar surfaces after the tests with the load of $0.5 \mathrm{~N}$ (Figure $\mathbf{2 b}-\mathbf{d}$ ). The surface asperities are gradually smoothed with increasing number of cycles from 36000 to 72000 cycles. The unpolished surface of the pristine diamond film still can be seen after the test with 72000 cycles. Ripple patterns can be observed on the surface after the test with 72000 cycles, in agreement with our previous studies [12-15]. 

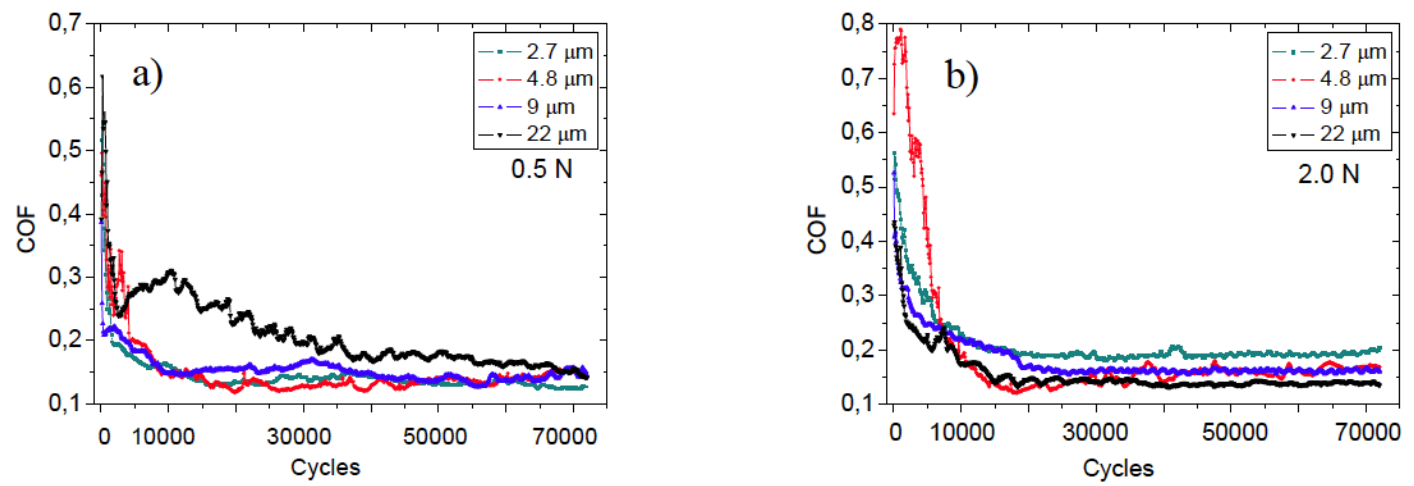

Figure 1: COF versus number of cycles curves corresponding to the tests with $0.5 \mathrm{~N}(\mathbf{a})$ and $2 \mathrm{~N}(\mathbf{b})$.
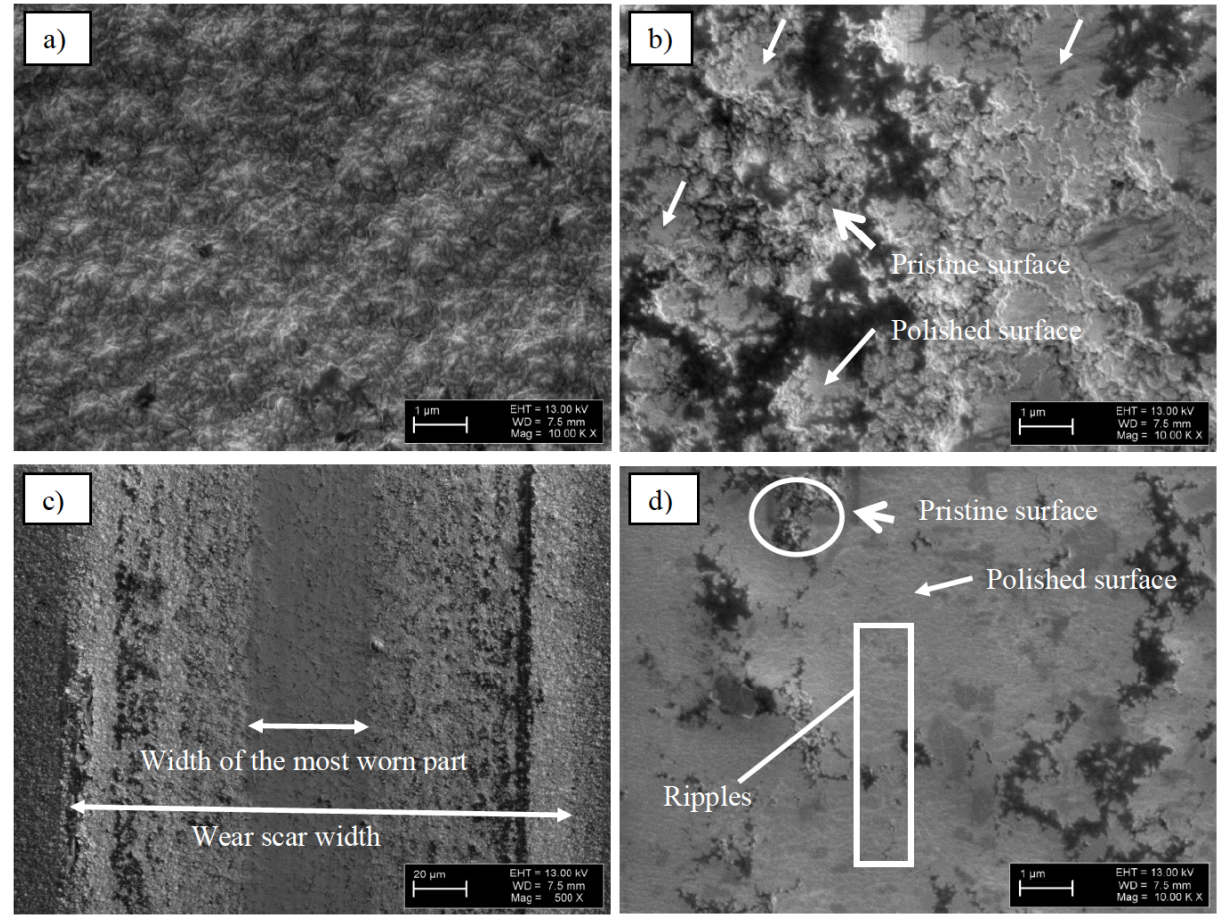

Figure 2: Surface morphology of the as-deposited $22 \mu \mathrm{m}$ thick NCD film (a) and the wear scars after the tests with the load of $0.5 \mathrm{~N}$ and the sliding durations of 36000 cycles (b) and 72000 cycles (c, d).

The transverse depth profiles were measured at 5 different locations on each wear scar after sliding tests with different loads and durations. The line scans shown in Figure $\mathbf{3}$ are obtained by averaging 5 depth profiles. The film deflection phenomenon can be understood by the analysis of SEM and profilometry data shown in Figures $\mathbf{2}$ and $\mathbf{3}$. The approximate position of the film surface shown in Figure $\mathbf{2} \mathbf{d}$ is depicted by a rectangular in Figure 3. The level of the border of the wear scar bed lies well below the level of the border of the most low-lying valleys of the pristine NCD film surface (Figure 3 ). It indicates that a part of the unpolished NCD film surface seen in Figure $\mathbf{2} \mathbf{d}$ is located below the level of the pristine NCD film surface. The film deflection value $(\Delta)$ is shown in Figure $\mathbf{3 b}$ for the test with 72000 cycles. The pristine surface of the NCD films within the wear scars was observed after the tests with 9000 cycles, it enables to compare the deflection of films with different thicknesses (Figure 4). The smallest film deflection was observed for the 9 and $22 \mu$ m thick films after the test with $0.5 \mathrm{~N}$. The $\Delta$ value increases with increasing load. It could be expected that the $\Delta$ value for the thicker films should be smaller than that for the thinner ones, due to higher load-carrying capacity of the thicker films [20]. No clear evidence of such trend was found (Figure 4), likely due to insufficient film thickness. However, an analysis of the shape of the wear scar profiles in Figure $\mathbf{3}$ provides an evidence of higher load-carrying capacity of the thicker films. The wear scar profile shapes tend to become more broader for the 22 $\mu \mathrm{m}$ thick film and more deeper for the $4.8 \mu \mathrm{m}$ thick film for the same value of load. This finding could be a consequence of the bending of films in the course of sliding, i.e. the thinner films are bended more strongly than the thicker ones, see Inserts in Figure $3 \mathbf{a}$ and $\mathbf{b}$. The higher COF value for $2.7 \mu \mathrm{m}$ thick film observed in tests with $2 \mathrm{~N}$ (Figure 1b) can be explained by film bending resulting in a higher contact area 

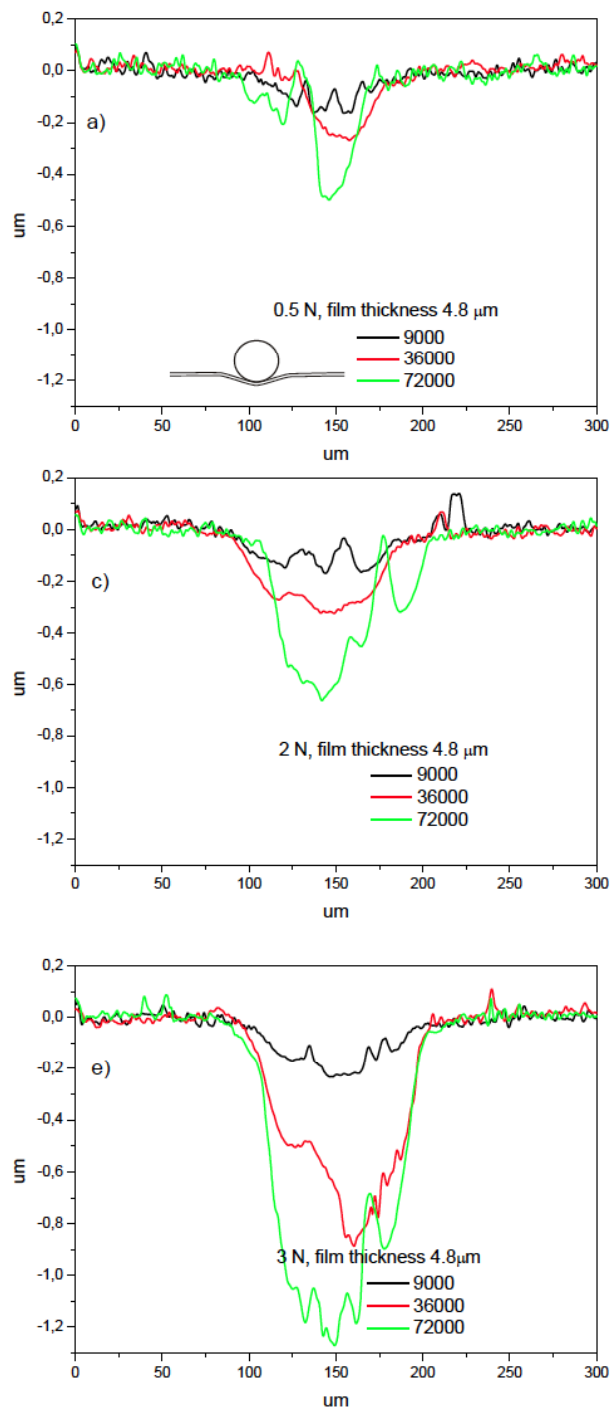

Figure 3: Depth profiles taken across the wear scars.

between the counterbodies [19, 20]. The aforementioned exfoliation of the $2.7 \mu \mathrm{m}$ thick films confirms also the lower load-carrying capacity of the thinner films. In other words, in analogy with nanoindentation measurements, elastic and plastic parts of deformation of the film/substrate system need to be taken into account to explain the film deflection phenomenon. Moreover, a higher $\Delta$ value was found after long-duration tests $(0.5 \mathrm{~N}, 36000$ and 72000 cycles) on the 22 thick film (Figure 4), thus a fatigue damage occurs in the diamond film/Si substrate tribosystem. The structural peculiarities of the diamond film/Si substrate system are shown in Figure 5. The dislocations network and hot-spots were discussed in Introduction. Following the publications by Williams et al. [30], Williams [31] and Setasuwon and Metanawin [32], a structure at the interface between the diamond film and the Si substrate is schematically shown in Figure 5. The properties of the diamond film structure formed during the early stage of the film growth can differ from those of the core part of diamond film. For instance, the diamond film surface asperities fracture occurs during the run-in
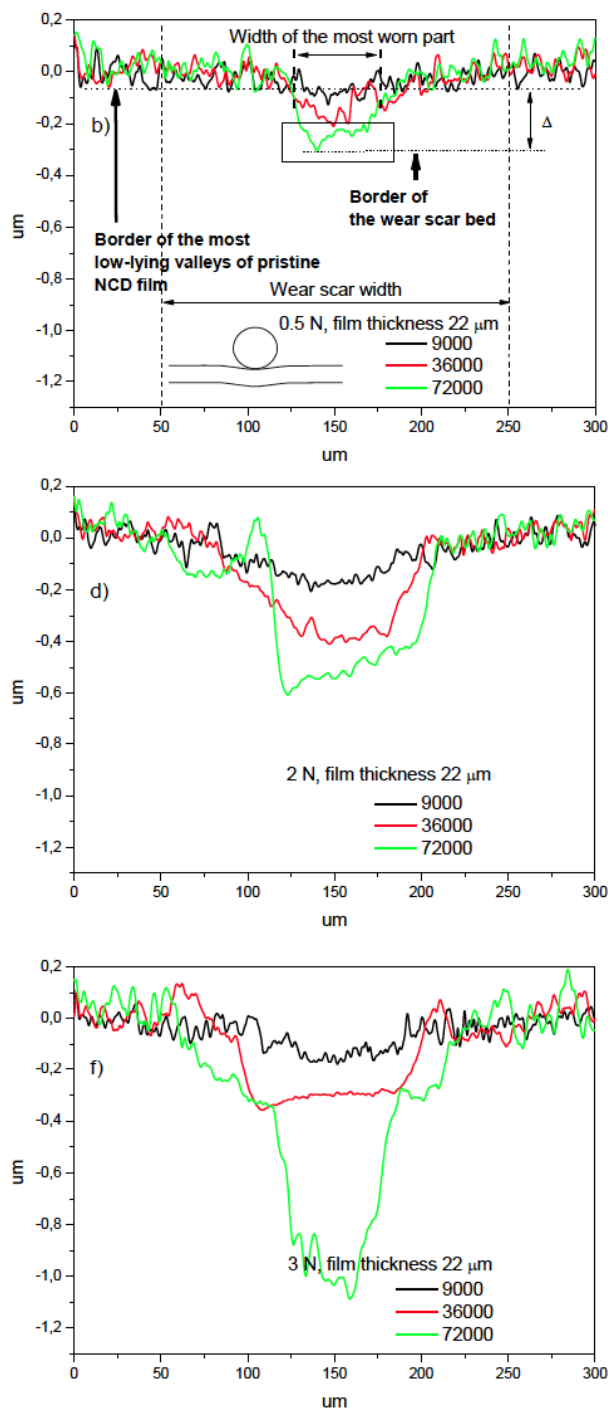

period. By analogy, the structure formed on the interface may not withstand the pressure in the system and may be

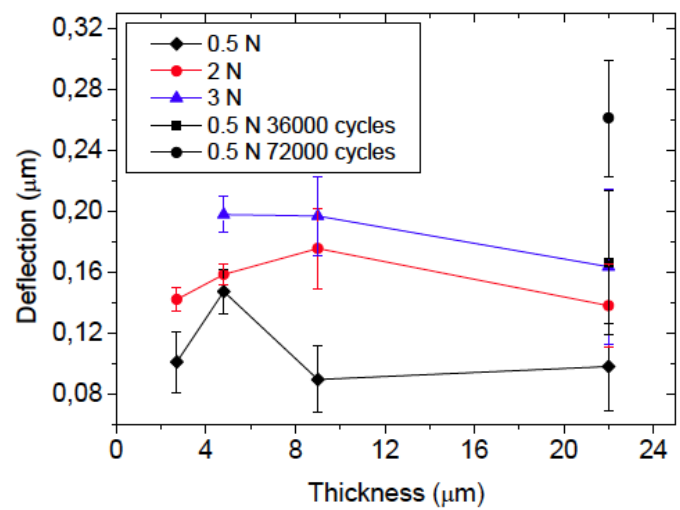

Figure 4: Film deflection value $(\Delta)$ measured after the tests with 9000 cycles for different loads. The $\Delta$ value is also shown for the tests with the load of $0.5 \mathrm{~N}$ (36000 and 72000 cycles) for the $22 \mu \mathrm{m}$ thick film, because the pristine film surface was observed. The error bars correspond to standard deviation. 
collapsed. On the other hand, a relatively small contact area between the seeding particles (the contact spots between the substrate and film in Figure 5) and the Si substrate can strongly influence contact pressure between the diamond films and substrate leading to deformation of the Si substrate.

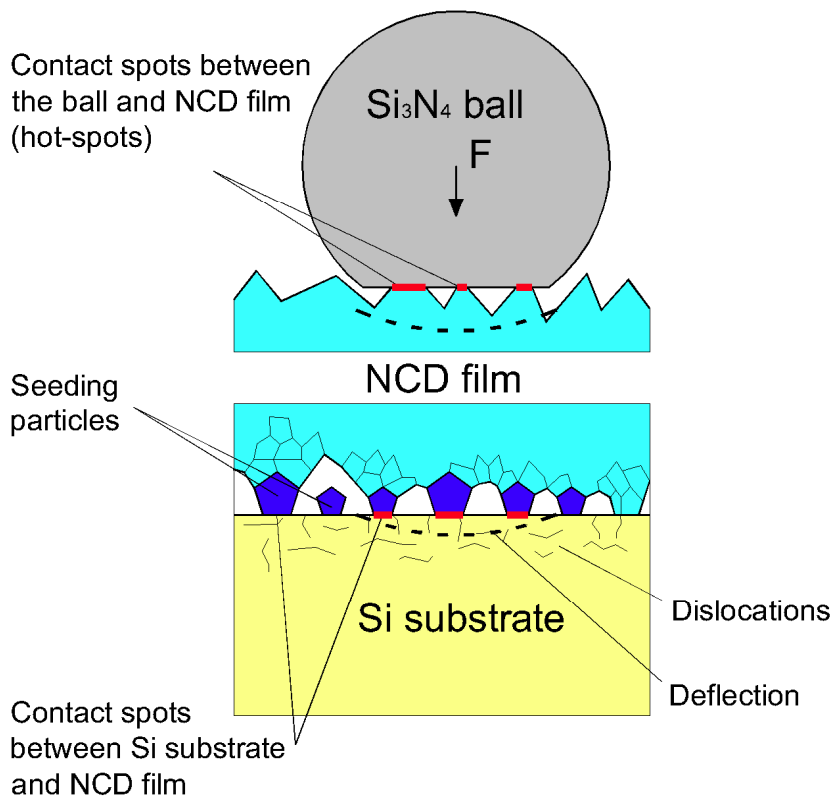

Figure 5: Model of the diamond film/Si substrate tribosystem.

The wear rate is calculated according equation $W=V /(F \times L)$, where $V$ is the wear volume loss, $F$ the normal load and $L$ the sliding distance. In the present study, the wear is affected by the film deflection, i.e. aforementioned equation, in principle, is not applicable for the calculation of wear rate of the diamond films and balls. Indeed, a fraction of the scar volume corresponding to the wear volume loss must be distinguished from a fraction related to the effect of film deflection. In addition, an interconnection between two processes leading to these effects should be taken into account i.e. mechanisms contributing to the film deflection can influence on the mechanisms contributing to the wear volume loss. For instance, a faster increase in the contact surface area during film deflection process can result in a greater decrease in the contact pressure and therefore slower material removal rate. In other words, the wear volume loss can differ for tribological systems with or without deflection. For the sake of comparison with data from literature, damage parameters $\left(W_{D}\right.$ and $\left.W_{B}\right)$ were calculated for the NCD films and $S_{3} N_{4}$ balls using wear rate equation. The volume of the scar is the product of the area of cross-section and the length of the scar. The area of the scar cross-section is the average area of 5 depth profiles taken on each scar, see text above. The value of $W_{D}$ calculated for the tests with the higher loads (2 and $3 \mathrm{~N}$ ) and longer duration (36000-72000 cycles) is about $1.5 \pm 0.5-4.5 \pm 1.2 \times 10^{-7} \mathrm{~mm}^{3} / \mathrm{Nm}$, which is similar to the value calculated according wear rate equation for NCD films and reported by Erdemir et al. [9, 11]. In the case of MCD films, similar values were found in our studies [15, 17]. It is important to stress that the type of measurement (diamond film, ball, substrate and tribological test conditions) in the mentioned studies $[9,11]$ was similar to the present one. The damage parameter for $\mathrm{Si}_{3} \mathrm{~N}_{4}$ balls was about $1 \pm 0.3 \times 10^{-7}$ $\mathrm{mm}^{3} / \mathrm{Nm}$ for the longer duration tests and similar value was found in the study [9]. The measurement uncertainty (standard deviation) was evaluated, the sample size was 3 scars (balls) produced with the same test parameters. Thus, the similarity between results indicates that the wear of the NCD films [9] could be affected by the film deflection as well.

Formation of carbonatious tribolayer was observed during run-in period (Figure 6a). The details of the Raman peaks identification can be found in our publications $[12,25]$. The peak at $1540 \mathrm{~cm}^{-1}$ ( $\mathrm{G}$ bands) corresponds to the in-plane stretching of $\mathrm{sp}^{2}$ bonds. A decrease of the diamond/sp $\mathrm{s}^{2}(\mathrm{G})$ peak intensity ratio for the wear scar surfaces allows to conclude that a stress-induced transition of diamond to $\mathrm{sp}^{2}$ bonding takes place, i.e. self-lubrication occurs in sliding tests, in agreement with previous study [12]. In addition, the surface smoothing and diamond films deflection reduce the contact pressure and wear of both mating surfaces. The EDS spectrum shows a relatively weak $\mathrm{Si}$ signal indicating wear of $\mathrm{Si}_{3} \mathrm{~N}_{4}$ balls (Figure $6 \mathbf{b}$ ). On the other hand, the results can be formulated in terms of entropy-based concept [33, 34]. The wear and friction are irreversible processes, however, because both are non-equilibrium processes self-organization

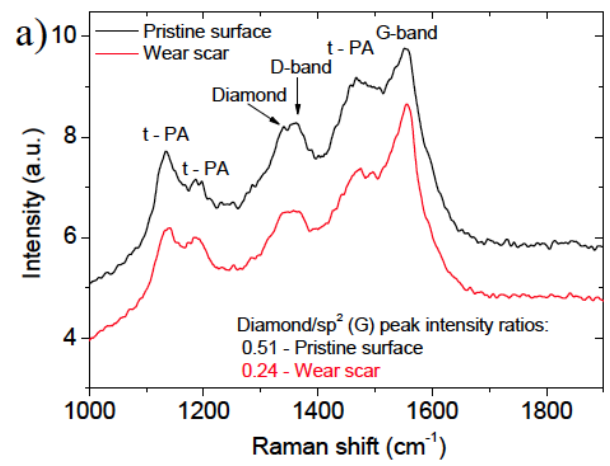

b)

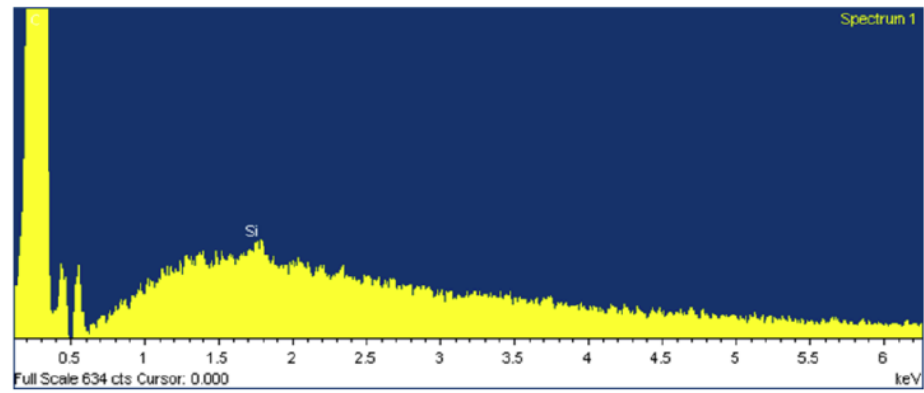

Figure 6: Raman spectra a) taken on the pristine $22 \mu \mathrm{m}$ thick film surface and the wear scar surface after the test with $0.5 \mathrm{~N}(72000 \mathrm{cycles})$. The diamond $/ \mathrm{sp}^{2}$ (G) peak intensity ratios derived from the Raman spectra. EDS spectrum b) was taken on the wear scar of $22 \mu \mathrm{m}$ thick film after the test with $0.5 \mathrm{~N}$ (72000 cycles). 
can already occur in system during run-in period, which minimizes entropy production rate (or wear and friction). In the broader context, the formation of tribolayer and morphological patterns [33], as well as the asperities smoothening and the film deflection can be viewed as selforganization processes or mutual adjustment of the surfaces in tribosystem. Finally, it is interesting to note that the asperities smoothening and the surface deflection occur on the micro and macro levels, respectively.

Additional studies should be conducted to investigate the influence of the film deflection to the formation of ripple patterns on the wear scar surfaces. It was shown that the load value affects to the shape and size of the ripples [13].

\section{CONCLUSIONS}

The study focuses on the influence of diamond films deflection on the tribological properties. The deflection of NCD films was found after the sliding tests with different loads and durations. The film deflection is fatigue-induced evolution of the film structure and shape. The formation of the carbonatious tribolayer indicates self-organization in tribosystem. The contact pressure decreases due to smoothening of the contacting surfaces and film deflection. These facts indicate the adaptation of mating sliding surfaces. The development of a more complete model for the wear rate calculation of the systems exhibiting different adaptation mechanisms is a challenge for the next researches.

\section{ACKNOWLEDMENTS}

This study was financially supported by the Estonian Ministry of Education and Research under target financing project IUT 19-29.

\section{REFERENCES}

[1] Haubner R, Kalss W. Diamond deposition on hardmetal substrates comparison of substrate pre-treatments and industrial applications. Int J Refract Met Hard Mater 2010; 28: 475-483.

http://dx.doi.org/10.1016/j.jijmhm.2010.03.004

[2] Auciello O, Birrell J, Carlisle JA, Gerbi JE, Xiao X, Peng B, Espinosa HD. Materials science and fabrication process for a new MEMS technology based on ultrananocrystalline diamond thin films. J Phys Condens Matter 2004; 16: R539-R552.

http://dx.doi.org/10.1088/issn.0953-8984

[3] Roy M, Haubner R. Surface Engineering for Enhanced Performance against Wear, Springer 2013

[4] Van Bouwelen FM, Enckevort WJP. A simple model to explain the anisotropy of diamond polishing. Diam Relat Mater 1999; 8: 840-844. http://dx.doi.org/10.1016/s0925-9635(98)00347-1

[5] Hird JR, Field JE. Diamond polishing. Proc R Soc Lond A 2004; 460: 3547-3568.

http://dx.doi.org/10.1098/rspa.2004.1339

[6] Pastewka L, Moser S, Gumbsch P, Moseler M. Anisotropic mechanical amorphization drives wear in diamond. Nat Mater 2011; 10: 34-38. http://dx.doi.org/10.1038/nmat2902

[7] Chromik RR, Winfrey AL, Lüning J, Nemanich RJ, Wahl KJ. Run-in behavior of nanocrystalline diamond coatings studied by in situ tribometry. Wear 2008; 265: 477-489.

http://dx.doi.org/10.1016/j.wear.2007.11.023
Konicek AR, Grierson DS, Sumant AV, Friedmann TA, Sullivan JP, Gilbert PUPA, Sawyer WG, Carpick RW. Influence of surface passivation on the friction and wear behavior of ultrananocrystalline diamond and tetrahedral amorphous carbon thin films. Phys Rev B 2012; 85: 155448-1-155448-13

http://dx.doi.org/10.1103/physrevb.85.155448

[9] Erdemir A, Halter M, Fenske GR, Zuiker C, Csencsits R, Krauss AR, Gruen DM. Friction and wear mechanisms of smooth diamond films during sliding in air and dry nitrogen. Tribol Trans 1997; 40: 667-675. http://dx.doi.org/10.1080/10402009708983707

[10] Bhushan B, Subramaniam VV, Malshe A, Gupta BK, Ruan J. Tribological properties of polished diamond films. J Appl Phys 1993; 74(6): 4174-4180.

http://dx.doi.org/10.1063/1.354421

[11] Erdemir A, Fenske GR, Krauss AR, Gruen DM, McCauley T, Csencsits RT. Tribological properties of nanocrystalline diamond films. Surf Coat Technol 1999; 120-121: 565-572. http://dx.doi.org/10.1016/s0257-8972(99)00443-0

[12] Podgursky V, Hantschel T, Bogatov A, Kimmari E, Antonov M, Viljus M, Mikli V, Tsigkourakos M, Vandevorst W, Buijnsters JG, Raadik AT, Kulu P. Rippling on wear scar surfaces of nanocrystalline diamond films after reciprocating sliding against ceramic balls. Tribol Lett 2014 55: 493-503. http://dx.doi.org/10.1007/s11249-014-0379-z

[13] Bogatov A, Podgursky V, Raadik AT, Kamjula AR, Hantschel T, Tsigkourakos M, Kulu P. Investigation of morphology changes on nanocrystalline diamond film surfaces during reciprocating sliding against $\mathrm{Si}_{3} \mathrm{~N}_{4}$ balls. Key Engineering Materials 2014; 604: 126-129. http://dx.doi.org/10.4028/www.scientific.net/10.4028/www.scientific.ne $\mathrm{t} / \mathrm{kem} .604 .126 \mathrm{kem} .604 .126$

[14] Bogatov A, Viljus M, Raadik T, Hantschel T, Podgursky V. Nanocrystalline diamond films deformation observed during sliding tests against $\mathrm{Si}_{3} \mathrm{~N}_{4}$ balls as a possible cause for ripple formation on wear scars. Materials Science (Medžiagotyra) 2015; 21: 349-352. http://dx.doi.org/10.5755//01.ms.21.3.7232

[15] Bogatov A, Traksmaa R, Podgursky V. Changes in surface morphology, deflection and wear of microcrystalline diamond film observed during sliding tests against $\mathrm{Si}_{3} \mathrm{~N}_{4}$ balls. Key Engineering Materials 2016; 674: 145-151.

http://dx.doi.org/10.4028/www.scientific.net/kem.674.145

[16] Blau PJ. On the nature of running-in. Tribol Int 2005; 38(11): 10071012.

\section{http://dx.doi.org/10.1016/.triboint.2005.07.020}

[17] Yashin M, Bogatov A, Podgursky V. Comparative analysis of wear rates of microcrystalline diamond and diamond-like carbon coatings deposited on WC-Co substrates. Accepted for Key Engineering Materials 2017.

[18] Holmberg K, Ronkainen H, Laukkanen A, Wallin K. Friction and wear of coated surfaces - scales, modeling and simulation of tribomechanisms. Surf Coat Technol 2007: 202: 1034-1049. http://dx.doi.org/10.1016/i.surfcoat.2007.07.105

[19] Holmberg K, Matthews A, Tribological Properties of Metallic and Ceramic Coatings, in Modern Tribology Handbook, (ed. B. Bhushan), 2/23, CRC Press, Boca Raton, USA 2001; $827-870$.

[20] Ronkainen $\mathrm{H}$, Koskinen J, Varjus S, Holmberg K. Load-carrying capacity evaluation of coating/substrate systems for hydrogen-free and hydrogenated diamond-like carbon films. Tribol Lett 1999; 6: 6373 .

\section{http://dx.doi.org/10.1023/a:1019107622768}

[21] Oliver WC, Pharr GM. Measurement of hardness and elastic modulus by instrumented indentation: advances in understanding and refinements to methodology. J Mater Res 2004; 19(1): 3-20. http://dx.doi.org/10.1557/jmr.2004.19.1.3

[22] Tsui TY, Pharr GM. Substrate effects on nanoindentation mechanical property measurement of soft films on hard substrates. J Mater Res 1999; 14(1): 292-301.

http://dx.doi.org/10.1557/imr.1999.0042

[23] Michler J, Mermoux M, von Kaenel Y, Haouni A, Lucazeau G, Blank E. Residual stress in diamond films: origins and modeling. Thin Solid Films 1999; 357(2): 189-201. http://dx.doi.org/10.1016/s0040-6090(99)00528-3

[24] Bowden FP, Freitag EH. The friction of solids at very high speeds. Proc R Soc A 1958; 248: 350-367. http://dx.doi.org/10.1098/rspa.1958.0248

[25] Podgursky V, Bogatov A, Sedov V, Sildos I, Mere A, Viljus M, Buijnsters JG, Ralchenko V. Growth dynamics of nanocrystalline diamond films produced by microwave plasma enhanced chemical 
vapor deposition in methane/hydrogen/air mixture: Scaling analysis of surface morphology. Diam Relat Mater 2015; 58: 172-179. http://dx.doi.org/10.1016/i.diamond.2015.07.002

[26] Bhushan B, Li X. Micromechanical and tribological characterization of doped single-crystal silicon and polysilicon films for microelectromechanical systems devices. J of Materials Research 1997; 12 (1): 54-63

http://dx.doi.org/10.1557/imr.1997.0010

[27] Boyd EJ, Uttamchandani D. Measurement of the anisotropy of Young's modulus in single-crystal silicon. $\mathrm{J}$ of Microelectromechanical Systems 2012; 21(1): 243-249.

http://dx.doi.org/10.1109//imems.2011.2174415

[28] Gan L, Ben-Nissan B, Ben-David A. Modelling and finite element analysis of ultra-microhardness indentation of thin films. Thin Solid Films 1996; 290-291: 362-366.

http://dx.doi.org/10.1016/s0040-6090(96)08972-9

[29] Ericson F, Schweitz J-A. Micromechanical fracture strength of silicon. J Appl Phys 1990; 68: 5840-5844.

http://dx.doi.org/10.1063/1.346957
[30] Williams OA, Nesladek M, Daenen M, Michaelson S, Hoffman A Osawa E, Haenen K, Jackman RB. Growth, electronic properties and applications of nanodiamond. Diam Relat Mater 2008; 17: 1080-1088. http://dx.doi.org/10.1016/j.diamond.2008.01.103

[31] Williams OA, Nanocrystalline diamond. Diam Relat Mater 2011; 20 621-640.

http://dx.doi.org/10.1016/..diamond.2011.02.015

[32] Setasuwona P, Metanawin T. Study of diamond film interface structure and contacting area. Materials Research 2009; 12(1): 89-94. http://dx.doi.org/10.1590/s1516-14392009000100011

[33] Nosonovsky M, Bhushan B. Thermodynamics of surface degradation self-organization and self-healing for biomimetic surfaces. Phil Trans R Soc A 2009; 367: 1607-1627.

http://dx.doi.org/10.1098/rsta.2009.0009

[34] Fox-Rabinovich GS, Totten GE, Eds. Self-organization during friction, Boca Raton, FL: CRC Press 2006. 